\title{
ORIGINAL
}

\section{Frailty and invasive mechanical ventilation: association with outcomes, extubation failure, and tracheostomy}

Shannon M. Fernando ${ }^{1,2^{*}}$ (1), Daniel I. Mclsaac ${ }^{3,4,5}$, Bram Rochwerg, ${ }^{6,7}$, Sean M. Bagshaw ${ }^{8}$, John Muscedere ${ }^{9}$, Laveena Munshi ${ }^{10,11}$, Niall D. Ferguson ${ }^{10,12}$, Andrew J. E. Seely ${ }^{1,4,5,13}$, Deborah J. Cook ${ }^{6,7}$, Chintan Dave ${ }^{14}$, Peter Tanuseputro ${ }^{4,5,15,16}$ and Kwadwo Kyeremanteng ${ }^{1,5,16,17}$

(c) 2019 Springer-Verlag GmbH Germany, part of Springer Nature

\begin{abstract}
Purpose: Invasive mechanical ventilation is a common form of life support provided to critically ill patients. Frailty is an emerging prognostic factor for poor outcome in the Intensive Care Unit (ICU); however, its association with adverse outcomes following invasive mechanical ventilation is unknown. We sought to evaluate the association between frailty, defined by the Clinical Frailty Scale (CFS), and outcomes of ICU patients receiving invasive mechanical ventilation.

Methods: We performed a retrospective analysis (2011-2016) of a prospectively collected registry from two hospitals of consecutive ICU patients $\geq 18$ years of age receiving invasive mechanical ventilation. CFS scores were based on recorded pre-admission function at the time of hospital admission. The primary outcome was hospital mortality. Secondary outcomes included discharge to long-term care, extubation failure at time of first liberation attempt, and tracheostomy.
\end{abstract}

Results: We included 8110 patients, and 2529 (31.2\%) had frailty (CFS $\geq 5$ ). Frailty was associated with increased odds of hospital death (adjusted odds ratio [aOR]: 1.24 [95\% confidence interval [Cl] 1.10-1.40) and discharge to long-term care (aOR 1.21 [95\% Cl 1.13-1.35]). As compared to patients without frailty, patients with frailty had increased odds of extubation failure (aOR 1.17 [95\% Cl 1.04-1.37]), hospital death following extubation failure (aOR 1.18 [95\% Cl 1.07-1.28]), tracheostomy (aOR 1.17 [95\% Cl 1.01-1.36]), and hospital death following tracheostomy $(\mathrm{aOR} 1.14$ [95\% Cl $1.03-1.25])$.

Conclusions: The presence of frailty among patients receiving mechanical ventilation is associated with increased odds of hospital mortality, discharge to long-term care, extubation failure, and need for tracheostomy.

Keywords: Frailty, Mechanical ventilation, Extubation failure, Tracheostomy

\footnotetext{
*Correspondence: sfernando@qmed.ca

${ }^{1}$ Division of Critical Care, Department of Medicine, University of Ottawa, Ottawa, ON, Canada
}

Full author information is available at the end of the article

\section{至




\section{Introduction}

Invasive mechanical ventilation remains a mainstay of life support therapy among critically ill patients. Of all patients admitted to the Intensive Care Unit (ICU), between 35 and $50 \%$ will require mechanical ventilation at some point during their admission [1-3]. Of these patients, roughly $35-40 \%$ will die in-hospital [4], though survival in this population has improved gradually over time [5]. Mechanical ventilation is also associated with significant morbidity, including muscle atrophy, infection, and delirium [6]. Overall costs from mechanical ventilation remain significant [3], and it has been consistently demonstrated to be one of the biggest drivers of cost among critically ill patients [7].

Approximately $10-20 \%$ of patients will ultimately fail to be liberated from mechanical ventilation, and may fail extubation, thus requiring re-intubation. Such patients are at increased risk of death $[8,9]$. Patients who fail extubation experience prolonged mechanical ventilation, and often require tracheostomy [10]. Therefore, there has been considerable focus on identification of prognostic factors associated with mortality and extubation failure in those receiving mechanical ventilation, to facilitate decision making with patients and their families regarding goals-of-care.

As a clinical state characterized by reduced physiologic reserve and increased vulnerability to physiological stresses [11], frailty has become recognized as an important prognostic indicator in critically ill patients [12]. In the ICU, screening for frailty is typically performed using the Clinical Frailty Scale (CFS) [13], which can be applied quickly and conveniently, and is associated with increased mortality and resource utilization in various ICU populations [14-18]. While the relationship between increasing age and poor outcomes among mechanically ventilated patients is well documented $[19,20]$, it is unclear whether this association is due to the higher prevalence of frailty in the elderly, or due to some other factor associated with aging. Importantly, frailty is not always synonymous with aging, and younger patients with significant comorbidities may also have frailty [21]. Overall, little is known regarding the association between frailty and outcomes following institution of invasive mechanical ventilation. Therefore, we sought to evaluate this relationship in ICU patients receiving mechanical ventilation, and in particular, to examine associations with hospital mortality, extubation failure, and tracheostomy.

\section{Methods}

Ethics approval for this study was obtained from The Ottawa Health Science Network Research Ethics Board (Protocol 20160570-01H).

\section{Take-home message}

Clinical frailty was associated with important outcomes following mechanical ventilation, including hospital mortality, disposition to long-term care, extubation failure, and tracheostomy. This prognostic factor may ultimately be useful in patient-provider discussions related to mechanical ventilation, and could be incorporated into future prediction models for clinical decision making.

\section{Study design, setting and subjects}

We studied patients at two hospitals within The Ottawa Hospital network (Ottawa, ON). Combined, both hospitals have approximately 2500 total ICU admissions per year. We retrospectively examined prospectively collected data from The Ottawa Hospital Data Warehouse, a health administrative database used in previous studies [22-24]. During hospital admission, daily data are gathered from each patient and stored in The Ottawa Hospital Data Warehouse. Data quality assessments are executed routinely, and quality-assurance initiatives are conducted regularly to ensure completeness and accuracy.

We included all patients $\geq 18$ years of age, admitted between 2011 and 2016, who received invasive mechanical ventilation, defined as mechanical ventilation delivered via endotracheal tube or tracheostomy. We excluded patients who only received non-invasive mechanical ventilation or high flow nasal cannulae. We also excluded patients with chronic invasive ventilation requirements at the time of hospital admission (since there would be no expectation of liberation from mechanical ventilation), and those with existing goals-of-care that did not allow for mechanical ventilation. We excluded patients with missing data related to baseline function prior to admission. Importantly, hospital mortality data from 791 patients (9.8\% of our study cohort) have been presented previously [18]. However, data related to extubation failure and tracheostomy among these patients have not been previously presented.

\section{Data collection}

All data were obtained from The Ottawa Hospital Data Warehouse. We abstracted basic demographic data, comorbidities, Elixhauser Comorbidity Score [25], and Multiple Organ Dysfunction Score (MODS) [26] at the time of ICU admission. The Elixhauser Comorbidity Index is generated from comorbidities stored in the Data Warehouse, and the association between this index and mortality has been previously validated in our database [27]. The most responsible diagnosis was recorded at death or discharge, based upon International Classification of Diseases, Version 10 (ICD-10). Outcome data 
were collected from admission until either the point of discharge from hospital, or hospital death.

As there is no consensus definition, we followed existing standards in defining "extubation failure" [28]. Since successful liberation has been defined as the absence of invasive ventilatory support during the first $48 \mathrm{~h}$ after extubation [29], we considered re-initiation of invasive mechanical ventilation within the first $48 \mathrm{~h}$ of extubation (i.e., removal of an endotracheal tube) to indicate "extubation failure". In keeping with evidence that non-invasive ventilation following extubation does not prevent re-intubation [30], we did not include initiation of noninvasive ventilation as constituting extubation failure. In the analysis of extubation failure, we excluded patients who were extubated with a "do not re-intubate" order, patients who were extubated to facilitate palliation, and those who required re-intubation strictly for a planned procedure, as determined from patient records. Need for percutaneous or open tracheostomy was confirmed through patient records, and further validated by review of chest X-ray reports.

The primary outcome was hospital mortality. Secondary outcomes included discharge directly from hospital to long-term care (among survivors to hospital discharge originally from home), extubation failure, tracheostomy, ICU LOS, hospital LOS, and hospital readmission within 30 days.

\section{Screening for frailty}

To identify the presence of frailty, we used the CFS, a 9-point global frailty scale which evaluates baseline mobility, energy, physical activity, and function (prior to hospital admission) [13]. We applied the CFS for each study patient as described previously [18]. Briefly, we evaluated patient pre-admission mobility and function assessments (prior to the acute illness), as completed by nursing staff or occupational therapy within $24 \mathrm{~h}$ of ICU admission. We used these staff assessments to retrospectively score each patient on the CFS, using a standardized abstraction tool (Supplemental Fig. 1). This method has been used previously in critically ill patients, and been shown to have comparable reliability to prospective assessment $[18,31]$. Patients with a CFS of 9 were excluded, given their high likelihood of short-term mortality. We performed abstraction from charts according to accepted standards [32]. To evaluate reproducibility in abstraction, two independent investigators (SMF, CD), blinded to each other's scores, individually evaluated a random sample of $20 \%$ of patient records. As inter-rater reliability was excellent $(\kappa=0.951)$, a single investigator (SMF) completed the remaining records. Consistent with previous research, a CFS $\geq 5$ was used to identify the presence of frailty $[15,17]$.

\section{Statistical analysis}

We performed all statistical analyses with $\mathrm{R}$ (Version 3.3.3) and IBM SPSS (Version 24.0). We present data as mean values, with standard deviation (SD), or medians, with interquartile range (IQR), where appropriate. The Student's $t$ test (parametric values), Mann-Whitney test (non-parametric values), and $\chi^{2}$ (for categorical values) were performed to determine between-group baseline differences. As recommended for observational studies in the critically ill [33], confounders were determined a priori, on the basis of their likelihood of influencing both the presence of frailty and associated outcomes, informed by clinical knowledge and existing studies evaluating the association between frailty and mortality in critically ill patients [14-16]. In accordance with the existing recommendations [33], we used multivariable logistic regression modeling to adjust for age, sex, illness severity [MODS], location of intubation and initiation of mechanical ventilation (ICU vs. non-ICU), most responsible diagnosis, and Elixhauser comorbidity index [25]. We present adjusted odds ratios (aOR) with 95\% confidence intervals. To evaluate the robustness of our findings, we performed post hoc sensitivity analyses excluding patients with severe frailty (CFS 8), and patients with limitations on care, either at the time of ICU admission or extubation. Finally, we followed the Prognosis Research Strategy guidelines in developing a predictive model for in-hospital mortality [34]. These guidelines recommend a clinical hypothesis-driven approach for a priori selection of all model variables, as opposed to bivariate association testing methods. We ensured the recommended sample size threshold of at least 10 events per predictor was met [35]. One thousand bootstrap samples with the same size as the original cohort were generated without replacement. Where a CI did not include 1 , the variable was considered to be a significant predictor.

For baseline characteristics, a $P$ value of $\leq 0.05$ was considered statistically significant. For outcomes, we applied a Bonferroni correction, and, therefore, a $P$ value of $<0.01$ was considered significant.

\section{Results}

A total of 17,173 patients were admitted to the participating ICUs from 2011 to 2016 (Supplemental Fig. 2). Of these, 8928 patients $(52.0 \%)$ were excluded, as they did not receive invasive mechanical ventilation. A further 41 patients $(0.5 \%)$ were excluded because of baseline chronic invasive ventilatory needs through permanent tracheostomy. Finally, 94 patients (1.1\%) were excluded due to insufficient available data allowing for CFS scoring.

In total, we included 8110 patients in the analyses. Of these patients, $2529(31.2 \%)$ had frailty $(\mathrm{CFS} \geq 5)$. 
Table 1 Characteristics of non-frail and frail ICU patients requiring mechanical ventilation $(n=8110)$

\begin{tabular}{|c|c|c|c|}
\hline Characteristic & No frailty $(n=5581)$ & Frailty $(n=2529)$ & $P$ value \\
\hline Age (years), mean (SD) & $57.6(18.1)$ & $69.2(12.2)$ & $<0.001$ \\
\hline Male, $n(\%)$ & $3227(57.8)$ & $1361(53.8)$ & $<0.01$ \\
\hline ICU MODS, mean (SD) & $4.8(2.6)$ & $5.2(2.7)$ & $<0.001$ \\
\hline \multicolumn{4}{|l|}{ Comorbidities } \\
\hline Congestive heart failure & $194(3.5)$ & $468(18.5)$ & $<0.001$ \\
\hline Atrial fibrillation & $590(10.6)$ & $457(18.1)$ & $<0.001$ \\
\hline Peripheral vascular disease & $222(4.0)$ & $301(11.9)$ & $<0.001$ \\
\hline Hypertension & $1382(24.8)$ & $775(30.7)$ & $<0.001$ \\
\hline Chronic obstructive pulmonary disease & $83(1.5)$ & $891(35.2)$ & $<0.001$ \\
\hline Diabetes mellitus & $1320(23.7)$ & $912(36.1)$ & $<0.001$ \\
\hline Chronic kidney disease & $182(3.3)$ & $170(6.8)$ & $<0.001$ \\
\hline Liver disease & $216(3.9)$ & $232(9.2)$ & $<0.001$ \\
\hline Malignancy & $413(7.4)$ & $601(23.8)$ & $<0.001$ \\
\hline Alcohol misuse & $329(5.9)$ & $166(6.6)$ & 0.24 \\
\hline Psychosis & $81(1.5)$ & $15(0.6)$ & $<0.01$ \\
\hline Depression & $178(3.2)$ & $44(1.7)$ & $<0.01$ \\
\hline Elixhauser Comorbidity Score, mean (SD) & $3.5(5.1)$ & $9.2(7.1)$ & $<0.001$ \\
\hline Daytime ICU admission (0800-1700), n (\%) & $3534(63.3)$ & $1742(68.9)$ & $<0.001$ \\
\hline Location prior to ICU admission, $n$ (\%) & & & $<0.001$ \\
\hline Emergency department & $2170(38.9)$ & $834(33.0)$ & \\
\hline Hospital wards & $1885(33.8)$ & $1090(43.1)$ & \\
\hline Operating room & $314(5.6)$ & $199(7.9)$ & \\
\hline Peripheral hospital & $1212(21.7)$ & $406(16.0)$ & \\
\hline Setting of intubation, $n(\%)$ & & & 0.24 \\
\hline ICU & $3182(57.0)$ & $1477(58.4)$ & \\
\hline Outside of ICU & $2399(43.0)$ & $1052(41.6)$ & \\
\hline Previous ED visits, mean (SD) ${ }^{a}$ & $2.2(2.6)$ & $2.3(1.8)$ & $<0.001$ \\
\hline Previous ICU admissions, mean (SD) ${ }^{a}$ & $0.2(0.6)$ & $0.5(1.2)$ & $<0.001$ \\
\hline Previous ICU days, mean (SD) ${ }^{a}$ & $1.3(5.7)$ & $4.3(15.0)$ & $<0.001$ \\
\hline No CPR directive at admission, $n(\%)$ & $692(12.4)$ & $701(27.7)$ & $<0.001$ \\
\hline Most responsible diagnosis, $n(\%)$ & & & $<0.001$ \\
\hline Infection/sepsis & $849(15.2)$ & $421(16.6)$ & \\
\hline Respiratory failure & $460(8.2)$ & $577(22.8)$ & \\
\hline Trauma & $821(14.7)$ & $88(3.5)$ & \\
\hline Malignancy & $394(7.1)$ & $248(9.8)$ & \\
\hline Spontaneous intracranial hemorrhage & $403(7.3)$ & $46(1.8)$ & \\
\hline Stroke & $288(5.2)$ & $61(2.4)$ & \\
\hline Overdose/poisoning & $242(4.3)$ & $7(0.3)$ & \\
\hline Renal failure & $97(1.7)$ & $46(1.8)$ & \\
\hline Gastrointestinal bleeding & $79(1.4)$ & $34(1.3)$ & \\
\hline Congestive heart failure & $20(0.4)$ & $67(2.6)$ & \\
\hline Cardiac arrest & $102(1.8)$ & $23(0.9)$ & \\
\hline Seizures/status epilepticus & $114(2.0)$ & $20(0.8)$ & \\
\hline Diabetic ketoacidosis & $51(0.9)$ & $37(1.5)$ & \\
\hline Other & $1661(29.8)$ & $854(33.8)$ & \\
\hline
\end{tabular}

CPR cardiopulmonary resuscitation, ED emergency department, ICU intensive care unit, MODS Multi-Organ Dysfunction Score, SD standard deviation

a Only including patients with previous visits to The Ottawa Hospital, and includes encounters prior to the index admission 
Baseline characteristics of non-frail and frail patients are shown in Table 1. Patients with frailty were older (mean age 69.2 years vs. 57.6 years, $P<0.001$ ), had higher severity of illness (mean MODS 5.2 vs. 4.8, $P<0.001$ ), and higher comorbidity burden. No difference in setting of intubation was seen between the groups. Respiratory failure was more common as an admitting diagnosis among patients with frailty compared to without $(22.8 \%$ vs. $8.2 \%$, $P<0.001)$.

Comparisons of outcomes between groups by frailty status are depicted in Table 2. Fully specified multivariable logistic regression analyses examining in-hospital mortality, extubation failure, and tracheostomy are displayed in the appendix (Supplemental Tables 1-3, respectively) as suggested by existing recommendations [33]. Patients with frailty had higher odds of hospital mortality (adjusted OR 1.24 [95\% CI 1.10-1.40]), extubation failure (adjusted OR 1.17 [95\% CI 1.04-1.37]), and tracheostomy (adjusted OR 1.17 [95\% CI 1.01-1.36]), as compared to people without frailty. The association between frailty and increased in-hospital mortality persisted in sensitivity analyses removing patients with the most severe frailty (CFS of 8 ), and those with limitations on care (Supplemental Tables 4,5). With regard to disposition, patients with frailty had a higher likelihood of discharge to a long-term care facility, as compared to those without frailty (adjusted OR 1.21 [95\% CI 1.13-1.35]). Finally, frailty was associated with longer median ICU LOS ( 7 days vs. 6 days, $P<0.001)$ and median total hospital LOS ( 15 days vs. 12 days, $P<0.001$ ). Figure 1 depicts liberation of mechanical ventilation over the course of the first 14 days following initiation of mechanical ventilation. At all measured time points, a higher proportion of non-frail than frail patients had been successfully liberated from mechanical ventilation. Evaluation of patients stratified by duration of mechanical ventilation found that frailty was associated with increased odds of mortality, extubation failure, and tracheostomy in all subgroups (Supplemental Table 6). Frailty was also found to be a significant predictor of in-hospital mortality in our logistic regression model (Supplemental Table 7).

A total of 1243 patients (15.3\%) in our cohort met criteria for extubation failure. Of these patients, 445 (35.8\%) had frailty. Comparison of those with and without frailty experiencing extubation failure is shown in Table 3 . Patients with frailty were significantly older than those without (mean 68.9 years vs. 57.6 years, $P<0.001$ ) and had higher severity of illness (mean MODS 5.9 vs. 5.4, $P<0.001)$. Patients with frailty experiencing extubation failure had a higher likelihood of death in-hospital, as compared to those without frailty (adjusted OR 1.18 [95\% CI 1.07-1.28]).

Finally, a total of $1470(18.1 \%)$ patients in our cohort required tracheostomy. Of these, 554 (37.7\%) had frailty. Comparison of patients receiving tracheostomy, by frailty status, is displayed in Table 4. A higher proportion of those with frailty underwent tracheostomy without prior attempt at extubation, as compared to patients without frailty $(68.0 \%$ vs. $61.5 \%, P<0.01)$, who were more likely to receive tracheostomy after extubation failure. No difference in timing of tracheostomy (relative to initiation of mechanical ventilation) was found between groups (median 9 days vs. 10 days, $P=0.31$ ). Patients with frailty were more likely than those without frailty to die

Table 2 Outcomes of non-frail and frail ICU patients requiring mechanical ventilation $(n=8110)$

\begin{tabular}{|c|c|c|c|c|}
\hline Characteristic & No frailty $(n=5581)$ & Frailty $(n=2529)$ & $\begin{array}{l}\text { Adjusted odds ratioc } \\
(95 \% \mathrm{Cl})\end{array}$ & $P$ value \\
\hline In-hospital mortality, n (\%) & $1617(29.0)$ & $1021(40.3)$ & $1.24(1.10-1.40)$ & $<0.001$ \\
\hline Extubation failure, $n(\%)^{\text {a }}$ & $798(14.9)$ & $445(19.9)$ & $1.17(1.04-1.37)$ & $<0.001$ \\
\hline Tracheostomy, $n$ (\%) & $916(17.1)$ & $544(24.4)$ & $1.17(1.01-1.36)$ & $<0.001$ \\
\hline Disposition, $n(\%)^{\mathrm{b}}$ & & & $1.21(1.13-1.35)$ & $<0.001$ \\
\hline Home & $2280(57.5)$ & $704(46.7)$ & & \\
\hline Long-term care center & $1684(42.5)$ & $804(53.3)$ & & \\
\hline ICU length of stay (days), median (IQR) & $6(2-12)$ & $7(4-14)$ & & $<0.001$ \\
\hline Hospital length of stay, days, median (IQR) & $12(4-28)$ & $15(7-32)$ & & $<0.001$ \\
\hline Ventilator-free days, median (IQR) & $7(1-19)$ & $6(2-20)$ & & $<0.001$ \\
\hline Readmission to ICU during hospitalization, $n$ (\%) & $921(16.5)$ & $463(18.3)$ & $1.04(0.98-1.11)$ & 0.07 \\
\hline Readmission within 30 days from discharge, $n(\%)^{\mathrm{b}}$ & $1187(29.9)$ & $416(27.6)$ & $1.09(0.87-1.21)$ & 0.19 \\
\hline
\end{tabular}

ICU intensive care unit, IQR interquartile range, MODS Multi-Organ Dysfunction Score, SD standard deviation

a Excludes patients where extubation was performed only for palliation, or who died prior to attempt at extubation

b Only includes patients surviving to discharge

c Ratio of frail patients to non-frail patients 


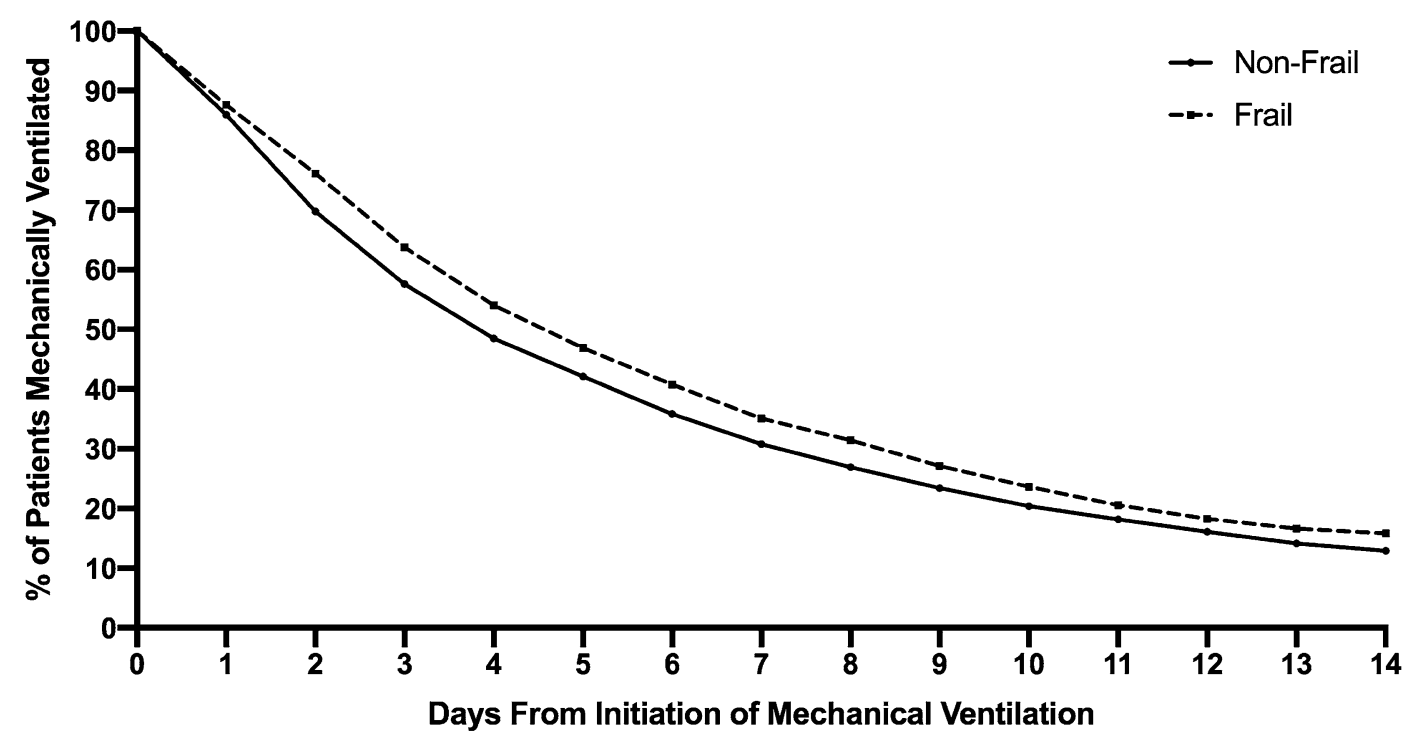

Fig. 1 Liberation from invasive mechanical ventilation over the first 14 days between frail and non-frail patients. $P<0.05$ at all points

in-hospital following tracheostomy (adjusted OR 1.14 [95\% CI 1.03-1.25]).

\section{Discussion}

Among critically ill adults requiring mechanical ventilation, we found that the presence of pre-admission frailty was associated with increased odds of extubation failure, tracheostomy, and hospital mortality, even after adjustment for age and other clinically relevant confounders. Ventilated patients with frailty were also more likely to be discharged to long-term care facilities than those without frailty, and more likely to have prolonged ICU and total hospital LOS. Finally, following extubation failure or receipt of tracheostomy, frailty was associated with increased risk of in-hospital death. Importantly, the relationship between frailty and these outcomes was independent of chronological age. These findings provide novel insight into the prognostic significance of frailty in predicting outcomes among critically ill adults requiring invasive mechanical ventilation.

The initiation of mechanical ventilation in a critically ill patient is an important event, and prior to offering this treatment, clinicians often discuss prognosis with patients and families [36]. The goal for the clinician at this point is often to not only explain the possible complications that may arise from mechanical ventilation, but also to discuss the likelihood of survival and future quality of life, and to inform goals-of-care discussions. In the elderly population, a growing evidence base suggests that patients with respiratory failure, even when treated with mechanical ventilation, have high mortality $[19,20,37]$. It is also evident that younger patients with a high burden of comorbidity (especially liver failure and chronic obstructive pulmonary disease) who require mechanical ventilation have a similarly poor prognosis $[38,39]$. This suggests that it may not simply be chronological age that determines outcome following critical illness and need for mechanical ventilation, but rather reduced physiologic reserve. Clinical frailty is aligned with this framework, and observational evidence to date strongly links frailty to worse outcomes in ICU patients, independent of age [14-18]. This study, specifically focusing on patients requiring mechanical ventilation, is consistent with these previous studies suggesting that the diagnosis of frailty may offer important prognostic information for patients, families, and clinicians to guide decision making and inform goals-of-care decisions [40].

These findings also place focus on the importance of frailty in predicting outcomes following extubation. Frailty was associated not only with extubation failure, but also predicted in-hospital death among patients experiencing extubation failure. Extubation failure is a critical event in ICU patients as, independent of illness severity, failing to wean from mechanical ventilation is associated with worse outcomes in critically ill patients $[9,28]$. Therefore, there is a growing need to identify factors predictive of failed extubation. While increasing age has been shown to be an independent predictor of extubation failure $[9,41]$, there is likely an additional effect of comorbidity, with one study demonstrating a fourfold higher risk in those with significant comorbidities [9]. Our findings, which support pre-ICU frailty as an important predictor of extubation failure independent of age and comorbidity, are also supported by clinically 
Table 3 Extubation failure and outcomes following extubation failure in non-frail and frail ICU patients requiring mechanical ventilation $(n=1243)$

\begin{tabular}{|c|c|c|c|c|}
\hline Characteristic & No frailty $(n=798)$ & Frailty $(n=445)$ & $\begin{array}{l}\text { Adjusted odds ratio } \\
(95 \% \mathrm{CI})^{\mathrm{b}}\end{array}$ & $P$ value \\
\hline Age (years), mean (SD) & $57.6(17.9)$ & $68.9(12.4)$ & & $<0.001$ \\
\hline Male, $n(\%)$ & $442(55.4)$ & $238(53.5)$ & & 0.52 \\
\hline ICU MODS, mean (SD) & $5.4(2.2)$ & $5.9(1.6)$ & & $<0.001$ \\
\hline \multicolumn{5}{|l|}{ Comorbidities } \\
\hline Congestive heart failure & $34(4.3)$ & $92(20.7)$ & & $<0.001$ \\
\hline Atrial fibrillation & $86(10.8)$ & $80(18.0)$ & & $<0.01$ \\
\hline Peripheral vascular disease & $26(3.3)$ & $61(13.7)$ & & $<0.001$ \\
\hline Hypertension & $179(22.4)$ & $139(31.2)$ & & $<0.001$ \\
\hline Chronic obstructive pulmonary disease & $19(2.4)$ & $36(8.1)$ & & $<0.001$ \\
\hline Diabetes mellitus & $194(24.3)$ & $156(35.1)$ & & $<0.001$ \\
\hline Chronic kidney disease & $29(3.6)$ & $27(6.1)$ & & 0.05 \\
\hline Liver disease & $38(4.8)$ & $48(10.8)$ & & $<0.001$ \\
\hline Malignancy & $43(5.4)$ & $99(22.2)$ & & $<0.001$ \\
\hline Alcohol misuse & $59(7.4)$ & $34(7.6)$ & & 0.87 \\
\hline Psychosis & $9(1.1)$ & $2(0.4)$ & & 0.22 \\
\hline Depression & $19(2.4)$ & $4(0.9)$ & & 0.06 \\
\hline Elixhauser Comorbidity Score, mean (SD) & $3.5(5.2)$ & $9.6(7.3)$ & & $<0.001$ \\
\hline Most responsible diagnosis, $n(\%)$ & & & & $<0.001$ \\
\hline Infection/sepsis & $140(17.5)$ & $83(18.7)$ & & \\
\hline Respiratory failure & $74(9.3)$ & $60(13.5)$ & & \\
\hline Trauma & $123(15.4)$ & $58(13.0)$ & & \\
\hline Malignancy & $35(4.4)$ & $38(8.5)$ & & \\
\hline Spontaneous intracranial hemorrhage & $66(8.3)$ & $16(3.6)$ & & \\
\hline Stroke & $32(4.0)$ & $8(1.8)$ & & \\
\hline Overdose/poisoning & $31(3.9)$ & $0(0)$ & & \\
\hline Renal failure & $10(1.3)$ & $9(2.0)$ & & \\
\hline Gastrointestinal bleeding & $9(1.1)$ & $4(0.9)$ & & \\
\hline Congestive heart failure & $2(0.3)$ & $19(4.3)$ & & \\
\hline Cardiac arrest & $19(2.4)$ & $9(2.0)$ & & \\
\hline Seizures/status epilepticus & $8(1.0)$ & $2(0.4)$ & & \\
\hline Diabetic ketoacidosis & $6(0.8)$ & $5(1.1)$ & & \\
\hline Other & $243(30.5)$ & $134(30.1)$ & & \\
\hline \multicolumn{5}{|l|}{ Outcomes following extubation failure, $n(\%)$} \\
\hline Died in-hospital & $196(24.6)$ & $147(33.0)$ & $1.18(1.07-1.28)$ & $<0.001$ \\
\hline Re-intubation, successful extubation, survival & $249(31.2)$ & $124(27.9)$ & $0.91(0.80-1.15)$ & 0.47 \\
\hline Re-intubation, tracheostomy, survival & $353(44.2)$ & $174(39.1)$ & $0.94(0.85-1.07)$ & 0.32 \\
\hline
\end{tabular}

ICU intensive care unit, IQR interquartile range, MODS Multi-Organ Dysfunction Score, SD standard deviation

a Excludes patients where extubation was performed only for palliation, or who died prior to attempt at extubation

b Ratio of frail patients to non-frail patients

plausible mechanisms. For example, frailty and sarcopenia often co-occur in older patients [42], and the muscle loss inherent in sarcopenia can impair the ability to take deep breaths and clear secretions. Whether frailty is associated with diaphragmatic dysfunction or puts patients at higher risk of ventilator-induced diaphragmatic dysfunction is unknown, but represents an avenue for future investigation. Finally, patients with frailty often have cognitive impairment and are at high risk of delirium [42] which may affect their ability to follow directions and expectorate effectively, and thereby contribute to extubation failure [28]. This suggests that frailty could act both as an important predictor, while also informing strategies to optimize extubation readiness. 
Table 4 Tracheostomy in non-frail and frail ICU patients requiring mechanical ventilation

\begin{tabular}{|c|c|c|c|c|}
\hline Characteristic & No frailty $(n=916)$ & Frailty $(n=544)$ & $\begin{array}{l}\text { Adjusted odds ratio } \\
(95 \% \mathrm{Cl})^{\mathrm{a}}\end{array}$ & $P$ value \\
\hline Age (years), mean (SD) & $56.8(17.0)$ & $68.3(12.3)$ & & $<0.001$ \\
\hline Male, $n(\%)$ & $527(57.5)$ & $307(56.4)$ & & 0.68 \\
\hline ICU MODS, mean (SD) & $4.9(2.3)$ & $5.3(1.9)$ & & $<0.01$ \\
\hline \multicolumn{5}{|l|}{ Comorbidities } \\
\hline Congestive heart failure & $49(5.3)$ & $115(21.1)$ & & $<0.001$ \\
\hline Atrial fibrillation & $141(15.4)$ & $114(21.0)$ & & $<0.01$ \\
\hline Peripheral vascular disease & $38(4.1)$ & $63(11.6)$ & & $<0.001$ \\
\hline Hypertension & $249(27.1)$ & $190(34.9)$ & & $<0.001$ \\
\hline Chronic obstructive pulmonary disease & $22(2.4)$ & $232(42.6)$ & & $<0.001$ \\
\hline Diabetes mellitus & $230(25.1)$ & $205(37.7)$ & & $<0.001$ \\
\hline Chronic kidney disease & $37(4.0)$ & $30(5.5)$ & & 0.19 \\
\hline Liver disease & $48(5.2)$ & $47(8.6)$ & & 0.01 \\
\hline Malignancy & $53(5.8)$ & $106(19.5)$ & & $<0.001$ \\
\hline Alcohol misuse & $38(4.1)$ & $34(6.3)$ & & 0.07 \\
\hline Psychosis & $10(1.1)$ & $3(0.6)$ & & 0.29 \\
\hline Depression & $26(2.8)$ & $5(0.9)$ & & 0.01 \\
\hline Elixhauser Comorbidity Score, mean (SD) & $4.2(5.3)$ & $9.1(7.0)$ & & $<0.001$ \\
\hline Most responsible diagnosis, $n(\%)$ & & & & $<0.001$ \\
\hline Infection/sepsis & $186(20.3)$ & $105(11.5)$ & & \\
\hline Respiratory failure & $134(14.6)$ & $107(19.7)$ & & \\
\hline Trauma & $155(16.9)$ & $33(6.1)$ & & \\
\hline Malignancy & $48(5.2)$ & $49(9.0)$ & & \\
\hline Spontaneous intracranial hemorrhage & $78(8.5)$ & $35(6.4)$ & & \\
\hline Stroke & $38(4.1)$ & $10(1.1)$ & & \\
\hline Overdose/poisoning & $11(1.2)$ & $0(0)$ & & \\
\hline Renal failure & $7(0.8)$ & $10(1.8)$ & & \\
\hline Gastrointestinal bleeding & $13(1.4)$ & $4(0.7)$ & & \\
\hline Congestive heart failure & $3(0.3)$ & $16(2.9)$ & & \\
\hline Cardiac arrest & $5(0.5)$ & $3(0.5)$ & & \\
\hline Seizures/status epilepticus & $6(0.7)$ & $3(0.5)$ & & \\
\hline Diabetic ketoacidosis & $6(0.7)$ & $5(0.9)$ & & \\
\hline Other & $226(24.7)$ & $144(15.7)$ & & \\
\hline \multicolumn{5}{|l|}{ Outcome } \\
\hline Tracheostomy following extubation, $n(\%)$ & $353(44.2)$ & $174(39.1)$ & & 0.01 \\
\hline Tracheostomy without extubation attempt, $n$ (\%) & $563(61.5)$ & $370(68.0)$ & & \\
\hline $\begin{array}{l}\text { Time from initiation of mechanical ventilation to trache- } \\
\text { ostomy (days), median (IQR) }\end{array}$ & $10(8-14)$ & $9(7-14)$ & & 0.34 \\
\hline In-hospital death following tracheostomy, n (\%) & $280(30.6)$ & $256(47.0)$ & $1.14(1.03-1.25)$ & $<0.01$ \\
\hline Tracheal infection, $n$ (\%) & $73(8.0)$ & $52(9.6)$ & $1.07(0.89-1.19)$ & 0.31 \\
\hline
\end{tabular}

ICU intensive care unit, IQR interquartile range, MODS Multi-Organ Dysfunction Score, SD standard deviation

a Ratio of frail patients to non-frail patients

Finally, we evaluated the association of frailty with incidence and outcomes following tracheostomy. In our cohort, roughly $18 \%$ of eligible patients underwent tracheostomy and ventilated patients with frailty were more likely to receive tracheostomy than non-frail counterparts. Additionally, frail patients were more likely to receive tracheostomy without an attempt at extubation. This may reflect a perceived higher risk of extubation failure among frail patients, which is supported by our findings. While tracheostomy is a necessary intervention in many patients requiring prolonged mechanical ventilation, it is also associated with important early and late 
complications, including infection, bleeding, fistulae, and tracheal stenosis [43]. Accordingly, in many situations, tracheostomy is a bridge to further therapy or recovery, and tracheostomy may be less likely to be pursued in situations of irreversible illness [10]. We found that frailty was associated with higher odds of in-hospital mortality following tracheostomy, again emphasizing the importance of considering this prognostic factor in discussion around patient-defined goals-of-care.

We used a large multicenter database of mechanically ventilated patients and identified patient- and health system-important associations between frailty and disease-specific outcomes. We also closely followed existing recommendations for control of confounding in observational studies [33]. However, our study has important limitations. Most importantly, decisions related to mechanical ventilation are made on the basis of patient-defined goals-of-care and may be influenced by indication bias. While data were available related to goals-of-care at the time of ICU admission, we do not have data on how these goals changed over the course of admission. Since patients living with frailty may be guided toward less aggressive treatments, this has the potential to bias our results. We performed a sensitivity analysis excluding patients with a pre-existing "No-CPR" order, and those extubated with a "Do-Not-Reintubate" order, which did not alter our conclusions. Second, we screened for frailty using the CFS in a retrospective fashion, although it was originally designed for prospective application [13]. While this has the potential to introduce bias, we used previously described methods [18], and followed best-practice recommendations for health record review methodology, through the use of multiple scorers and combined agreement [32]. These retrospective methods have been shown to have strong concordance with prospective CFS scoring in the ICU [31]. Third, with regard to extubation failure, data were not sufficiently granular to evaluate the association of frailty with other factors that may predict extubation failure. In particular, data related to weaning and physiotherapy protocols were unavailable. Such protocols may potentially have a greater relative effect upon patients with frailty than those without frailty, and as such, the absence of these data represents an important limitation to our work, particularly as it relates to associations between frailty, extubation failure, and tracheostomy. Furthermore, we lack data regarding the timing of initiation of mechanical ventilation relative to patient deterioration. Whether earlier ventilatory intervention among frail patients with respiratory failure is associated with outcomes is unknown. Finally, we did not have data related to long-term outcomes among survivors of mechanical ventilation. While frail patients may survive their admission, their long-term outcomes may be similarly poor. Addressing value in healthcare delivery is a major current focus of critical care $[44,45]$, and understanding the impact of frailty on long-term survival and quality of life will provide greater insight into whether provision of critical care in this population is truly beneficial. Future work should evaluate the association between frailty and long-term survival and disability following mechanical ventilation.

\section{Conclusions}

We found that, among ICU patients requiring mechanical ventilation, the presence of frailty increased the likelihood of short-term mortality, discharge to long-term care, extubation failure, and tracheostomy, even after adjustment for potential confounders. These findings have important implications in the risk stratification of all patients requiring mechanical ventilation, and may have a role in informed shared decision making with patients and families prior to the provision of mechanical ventilation.

\section{Electronic supplementary material}

The online version of this article (https://doi.org/10.1007/s00134-019-05795-8) contains supplementary material, which is available to authorized users.

\section{Author details \\ ${ }^{1}$ Division of Critical Care, Department of Medicine, University of Ottawa, Ottawa, ON, Canada. ${ }^{2}$ Department of Emergency Medicine, University of Ottawa, Ottawa, ON, Canada. ${ }^{3}$ Department of Anesthesiology and Pain Medicine, University of Ottawa, Ottawa, ON, Canada. ${ }^{4}$ School of Epidemiol- ogy and Public Health, University of Ottawa, Ottawa, ON, Canada. ${ }^{5}$ Clinical Epidemiology Program, Ottawa Hospital Research Institute, Ottawa, ON, Canada. ${ }^{6}$ Division of Critical Care, Department of Medicine, McMaster University, Hamilton, ON, Canada. ${ }^{7}$ Department of Health Research Methods, Evidence, and Impact, McMaster University, Hamilton, ON, Canada. ${ }^{8}$ Depart- ment of Critical Care Medicine, Faculty of Medicine and Dentistry, University of Alberta, Edmonton, AB, Canada. ${ }^{9}$ Department of Critical Care Medicine, Queen's University, Kingston, ON, Canada. ${ }^{10}$ Interdepartmental Division of Critical Care Medicine, University of Toronto, Toronto, ON, Canada. ${ }^{11}$ Depart- ment of Medicine, Sinai Health System, Toronto, ON, Canada. ${ }^{12}$ Toronto General Hospital Research Institute, University Health Network, Toronto, ON, Canada. ${ }^{13}$ Department of Surgery, University of Ottawa, Ottawa, ON, Canada. ${ }^{14}$ Department of Medicine, University of Ottawa, Ottawa, ON, Canada. ${ }^{15}$ Bruyere Research Institute, Ottawa, ON, Canada. ${ }^{16}$ Division of Palliative Care, Department of Medicine, University of Ottawa, Ottawa, ON, Canada. ${ }^{17}$ Institut du Savoir Montfort, Ottawa, ON, Canada.}

\section{Author contributions}

SMF, DIM, BR, SMB, JM, and KK designed the study. SMF, CD, and KK gathered the data. SMF, DIM, BR, SMB, JM, LM, NDF, AJES, DJC, PT, and KK analyzed the data. All the authors wrote the manuscript.

\section{Funding}

None.

\section{Compliance with ethical standards}

\section{Conflicts of interest}

Dr. Daniel I. Mclsaac is supported by the Canadian Anesthesiologists' Society Career Scientist Award. Dr. Sean M. Bagshaw is supported by a Canada Research Chair in Critical Care Nephrology. Dr. John Muscedere is the Scientific Director of the Canadian Frailty Network. Dr. Andrew J. E. Seely holds patents related to multiorgan variability analysis, and has shares in Therapeutic 
Monitoring Systems Inc. Dr. Deborah J. Cook is supported by a Canada Research Chair in Critical Care Knowledge Translation. None of the other authors report any conflict of interest.

\section{Publisher's Note}

Springer Nature remains neutral with regard to jurisdictional claims in published maps and institutional affiliations.

\section{Received: 15 June 2019 Accepted: 22 September 2019} Published online: 8 October 2019

\section{References}

1. Esteban A, Anzueto A, Frutos F, Alia I, Brochard L, Stewart TE, Benito S, Epstein SK, Apezteguia C, Nightingale P, Arroliga AC, Tobin MJ (2002) Characteristics and outcomes in adult patients receiving mechanical ventilation: a 28-day international study. JAMA 287:345-355

2. Esteban A, Anzueto A, Alia I, Gordo F, Apezteguia C, Palizas F, Cide D, Goldwaser R, Soto L, Bugedo G, Rodrigo C, Pimentel J, Raimondi G, Tobin MJ (2000) How is mechanical ventilation employed in the intensive care unit? An international utilization review. Am J Respir Crit Care Med 161:1450-1458

3. Wunsch $\mathrm{H}$, Linde-Zwirble WT, Angus DC, Hartman ME, Milbrandt EB, Kahn JM (2010) The epidemiology of mechanical ventilation use in the United States. Crit Care Med 38:1947-1953

4. Azevedo LC, Park M, Salluh Jl, Rea-Neto A, Souza-Dantas VC, Varaschin P, Oliveira MC, Tierno PF, dal-Pizzol F, Silva UV, Knibel M, Nassar AP Jr, Alves RA, Ferreira JC, Teixeira C, Rezende V, Martinez A, Luciano PM, Schettino G, Soares M (2013) Clinical outcomes of patients requiring ventilatory support in Brazilian intensive care units: a multicenter, prospective, cohort study. Crit Care 17:R63

5. Esteban A, Frutos-Vivar F, Muriel A, Ferguson ND, Penuelas O, Abraira V, Raymondos K, Rios F, Nin N, Apezteguia C, Violi DA, Thille AW, Brochard L, Gonzalez M, Villagomez AJ, Hurtado J, Davies AR, Du B, Maggiore SM, Pelosi P, Soto L, Tomicic V, D’Empaire G, Matamis D, Abroug F, Moreno RP, Soares MA, Arabi Y, Sandi F, Jibaja M, Amin P, Koh Y, Kuiper MA, Bulow $\mathrm{HH}$, Zeggwagh AA, Anzueto A (2013) Evolution of mortality over time in patients receiving mechanical ventilation. Am J Respir Crit Care Med 188:220-230

6. Goligher EC, Ferguson ND, Brochard LJ (2016) Clinical challenges in mechanical ventilation. Lancet 387:1856-1866

7. Dasta JF, McLaughlin TP, Mody SH, Piech CT (2005) Daily cost of an intensive care unit day: the contribution of mechanical ventilation. Crit Care Med 33:1266-1271

8. Thille AW, Cortes-Puch I, Esteban A (2013) Weaning from the ventilator and extubation in ICU. Curr Opin Crit Care 19:57-64

9. Thille AW, Harrois A, Schortgen F, Brun-Buisson C, Brochard L (2011) Outcomes of extubation failure in medical intensive care unit patients. Crit Care Med 39:2612-2618

10. Cheung NH, Napolitano LM (2014) Tracheostomy: epidemiology, indications, timing, technique, and outcomes. Respir Care 59:895-915

11. Xue QL (2011) The frailty syndrome: definition and natural history. Clin Geriatr Med 27:1-15

12. Muscedere J, Waters B, Varambally A, Bagshaw SM, Boyd JG, Maslove D, Sibley S, Rockwood K (2017) The impact of frailty on intensive care unit outcomes: a systematic review and meta-analysis. Intensive Care Med 43:1105-1122

13. Rockwood K, Song X, MacKnight C, Bergman H, Hogan DB, McDowell I, Mitnitski A (2005) A global clinical measure of fitness and frailty in elderly people. CMAJ 173:489-495

14. Bagshaw SM, Stelfox HT, McDermid RC, Rolfson DB, Tsuyuki RT, Baig N, Artiuch B, Ibrahim Q, Stollery DE, Rokosh E, Majumdar SR (2014) Association between frailty and short- and long-term outcomes among critically ill patients: a multicentre prospective cohort study. CMAJ 186:E95-102

15. Brummel NE, Bell SP, Girard TD, Pandharipande PP, Jackson JC, Morandi A, Thompson JL, Chandrasekhar R, Bernard GR, Dittus RS, Gill TM, Ely EW (2017) Frailty and subsequent disability and mortality among patients with critical illness. Am J Respir Crit Care Med 196:64-72
16. Zampieri FG, Iwashyna TJ, Viglianti EM, Taniguchi LU, Viana WN, Costa R, Correa TD, Moreira CEN, Maia MO, Moralez GM, Lisboa T, Ferez MA, Freitas CEF, de Carvalho CB, Mazza BF, Lima MFA, Ramos GV, Silva AR, Bozza FA, Salluh JIF, Soares M (2018) Association of frailty with short-term outcomes, organ support and resource use in critically ill patients. Intensive Care Med 44:1512-1520

17. Le Maguet $P$, Roquilly A, Lasocki S, Asehnoune K, Carise E, Saint Martin M, Mimoz O, Le Gac G, Somme D, Cattenoz C, Feuillet F, Malledant Y, Seguin $P$ (2014) Prevalence and impact of frailty on mortality in elderly ICU patients: a prospective, multicenter, observational study. Intensive Care Med 40:674-682

18. Fernando SM, Mclsaac DI, Perry JJ, Rochwerg B, Bagshaw SM, Thavorn K, Seely AJE, Forster AJ, Fiest KM, Dave C, Tran A, Reardon PM, Tanuseputro P, Kyeremanteng K (2019) Frailty and associated outcomes and resource utilization among older ICU patients with suspected infection. Crit Care Med 47:e669-e676

19. Cohen IL, Lambrinos J (1995) Investigating the impact of age on outcome of mechanical ventilation using a population of 41,848 patients from a statewide database. Chest 107:1673-1680

20. Barnato AE, Albert SM, Angus DC, Lave JR, Degenholtz HB (2011) Disability among elderly survivors of mechanical ventilation. Am J Respir Crit Care Med 183:1037-1042

21. Kehler DS, Ferguson T, Stammers AN, Bohm C, Arora RC, Duhamel TA, Tangri N (2017) Prevalence of frailty in Canadians 18-79 years old in the Canadian Health Measures Survey. BMC Geriatr 17:28

22. Fernando SM, Reardon PM, Rochwerg B, Shapiro NI, Yealy DM, Seely AJE, Perry JJ, Barnaby DP, Murphy K, Tanuseputro P, Kyeremanteng K (2018) Sepsis-3 septic shock criteria and associated mortality among infected hospitalized patients assessed by a rapid response team. Chest 154:309-316

23. Fernando SM, Reardon PM, Dowlatshahi D, English SW, Thavorn K, Tanuseputro P, Perry JJ, Rosenberg E, Wijdicks EF, Heyland DK, Kyeremanteng K (2018) Outcomes and costs of patients admitted to the ICU due to spontaneous intracranial hemorrhage. Crit Care Med 46:e395-e403

24. Fernando SM, Reardon PM, Mclsaac DI, Eagles D, Murphy K, Tanuseputro P, Heyland DK, Kyeremanteng K (2018) Outcomes of older hospitalized patients requiring rapid response team activation for acute deterioration. Crit Care Med 46:1953-1960

25. Elixhauser A, Steiner C, Harris DR, Coffey RM (1998) Comorbidity measures for use with administrative data. Med Care 36:8-27

26. Marshall JC, Cook DJ, Christou NV, Bernard GR, Sprung CL, Sibbald WJ (1995) Multiple organ dysfunction score: a reliable descriptor of a complex clinical outcome. Crit Care Med 23:1638-1652

27. van Walraven C, Austin PC, Jennings A, Quan H, Forster AJ (2009) A modification of the Elixhauser comorbidity measures into a point system for hospital death using administrative data. Med Care 47:626-633

28. Thille AW, Richard JC, Brochard L (2013) The decision to extubate in the intensive care unit. Am J Respir Crit Care Med 187:1294-1302

29. Boles JM, Bion J, Connors A, Herridge M, Marsh B, Melot C, Pearl R, Silverman H, Stanchina M, Vieillard-Baron A, Welte T (2007) Weaning from mechanical ventilation. Eur Respir J 29:1033-1056

30. Perkins GD, Mistry D, Gates S, Gao F, Snelson C, Hart N, Camporota L, Varley J, Carle C, Paramasivam E, Hoddell B, McAuley DF, Walsh TS, Blackwood B, Rose L, Lamb SE, Petrou S, Young D, Lall R (2018) Effect of protocolized weaning with early extubation to noninvasive ventilation vs invasive weaning on time to liberation from mechanical ventilation among patients with respiratory failure: the breathe randomized clinical trial. JAMA 320:1881-1888

31. Shears M, Takaoka A, Rochwerg B, Bagshaw SM, Johnstone J, Holding A, Tharmalingam S, Millen T, Clarke F, Rockwood K, Li G, Thabane L, Muscedere J, Stelfox HT, Cook DJ (2018) Assessing frailty in the intensive care unit: a reliability and validity study. J Crit Care 45:197-203

32. Worster A, Haines T (2004) Advanced statistics: understanding medical record review (MRR) studies. Acad Emerg Med 11:187-192

33. Lederer DJ, Bell SC, Branson RD, Chalmers JD, Marshall R, Maslove DM, Ost DE, Punjabi NM, Schatz M, Smyth AR, Stewart PW, Suissa S, Adjei AA, Akdis CA, Azoulay E, Bakker J, Ballas ZK, Bardin PG, Barreiro E, Bellomo R, Bernstein JA, Brusasco V, Buchman TG, Chokroverty S, Collop NA, Crapo JD, Fitzgerald DA, Hale L, Hart N, Herth FJ, Iwashyna TJ, Jenkins G, Kolb M, Marks GB, Mazzone P, Moorman JR, Murphy TM, Noah TL, Reynolds P, Riemann D, Russell RE, Sheikh A, Sotgiu G, Swenson ER, Szczesniak R, 
Szymusiak R, Teboul JL, Vincent JL (2019) Control of confounding and reporting of results in causal inference studies. guidance for authors from editors of respiratory, sleep, and critical care journals. Ann Am Thorac Soc 16:22-28

34. Steyerberg EW, Moons KG, van der Windt DA, Hayden JA, Perel P, Schroter S, Riley RD, Hemingway H, Altman DG (2013) Prognosis Research Strategy (PROGRESS) 3: prognostic model research. PLoS Med 10:e1001381

35. Peduzzi P, Concato J, Kemper E, Holford TR, Feinstein AR (1996) A simulation study of the number of events per variable in logistic regression analysis. J Clin Epidemiol 49:1373-1379

36. Swinburne AJ, Fedullo AJ, Bixby K, Lee DK, Wahl GW (1993) Respiratory failure in the elderly. analysis of outcome after treatment with mechanical ventilation. Arch Intern Med 153:1657-1662

37. Angus DC (2017) Admitting Elderly patients to the intensive care unit-is it the right decision? JAMA 318:1443-1444

38. Rabe C, Schmitz V, Paashaus M, Musch A, Zickermann H, Dumoulin FL, Sauerbruch T, Caselmann WH (2004) Does intubation really equal death in cirrhotic patients? Factors influencing outcome in patients with liver cirrhosis requiring mechanical ventilation. Intensive Care Med 30:1564-1571

39. Nevins ML, Epstein SK (2001) Predictors of outcome for patients with COPD requiring invasive mechanical ventilation. Chest 119:1840-1849

40. Luce JM (2010) End-of-life decision making in the intensive care unit. Am J Respir Crit Care Med 182:6-11

41. Epstein SK, Ciubotaru RL, Wong JB (1997) Effect of failed extubation on the outcome of mechanical ventilation. Chest 112:186-192

42. Arendts G, Burkett E, Hullick C, Carpenter CR, Nagaraj G, Visvanathan R (2017) Frailty, thy name is. Emerg Med Australas 29:712-716

43. Epstein SK (2005) Late complications of tracheostomy. Respir Care 50:542-549

44. Kyeremanteng K, Downar J (2019) Why is it so hard to stop doing things that are unwanted, non-beneficial, or unsustainable? Lancet Respir Med 7:558-560

45. Stelfox HT, Bourgault AM, Niven DJ (2019) De-implementing low value care in critically ill patients: a call for action-less is more. Intensive Care Med 45(10):1443-1446 